\title{
Quality of Road Trauma Data in Malawi: The Case of Road Trauma Surveillance in Ntcheu District, Malawi.
}

Steven Derrick Manyozo ( $\sim$ derrickmanyozo@gmail.com )

University of Malawi College of Medicine https://orcid.org/0000-0002-1448-7345

Wantula Sichembe

Ministry of Health, Lusaka

Rob Moodie

The University of Melbourne School of Population and Global Health

\section{Research article}

Keywords: Road trauma, Surveillance, capture-recapture, epidemiology, Malawi

Posted Date: July 24th, 2020

DOI: https://doi.org/10.21203/rs.3.rs-48094/v1

License: @) (7) This work is licensed under a Creative Commons Attribution 4.0 International License. Read Full License 


\section{Abstract}

Background Road trauma represents a major but neglected public health challenge in Malawi that requires concerted efforts for effective and sustainable prevention. In order to make the road traffic system safer, it is important to develop an understanding of the whole system and its elements including vehicles, roads and road-users along with their physical, social and environmental circumstances. In this study, we measured data quality in terms of database and variable completeness of road trauma case reports to determine if the data are sufficient for informing, monitoring and evaluating road safety interventions.

Methods This was a quantitative retrospective study based in Ntcheu district, Malawi. Data were collected for year 2018 from both police and hospital sources. Categorical data exploration from these two sources was done using frequency distribution tables. Continuous data were summarized using means and standard deviation. Data source completeness was assessed using the capture-recapture methodology, while variable completeness was assessed using a checklist developed from the World Health Organization's minimum injury surveillance core data set.

Results The hospital data source was incomplete in areas of road user type, time of injury, mechanism of injury and place of injury. Thirteen case matches were identified between the two databases. Using the capture-recapture methods, the estimated road trauma events in Ntcheu district for the year 2018 is 954 (95\% Cl: 457,1451$)$ and an estimated 173 deaths $(95 \% \mathrm{Cl}: 89,257)$ in the same year. These estimates indicate $11 \%$ and $14 \%$ ascertainment of fatalities for the police and hospital data sources respectively.

Discussion and conclusion There is significant underreporting for road deaths and injuries in Ntcheu district, which means there are critical data quality challenges in the respective data sources. It is therefore imperative for the road safety agencies and partners to resolve these data reporting and acquisition challenges.

\section{Introduction}

Road trauma continues to be an important global public health problem, contributing to over 1.35 million deaths and up to 50 million injuries world-wide annually [1][5]. Progress to reduce deaths due to road crashes globally has not been uniform, and low and middle income countries (LMIC) continue to share a disproportionately high burden (90\%) of road traffic deaths and injuries [1][2]. Furthermore, $50 \%$ of road trauma victims are vulnerable road users, including cyclists and pedestrians [3]. The 2018 Global Status Report on Road Safety recorded road trauma as the leading cause of death among young people aged 529 and the eighth highest cause of death across all age groups [3]. The targeted numbers of annual deaths - neither the 900,000 proposed by the original Decade nor the 650,000 included in the later SDG 3.6 - are likely to be reached by end of 2020 [4][5].

Malawi has one of the highest estimated rates of road traffic mortality per 100,000 residents of any country in the world [4]. Like many other LMIC, estimates of the magnitude of road traffic crashes, injuries and deaths are primarily obtained from police records, and sometimes hospital based registries, both of which have been reported to be insufficient [6][7]. Samuel et al. (2012) emphasized the need to examine the completeness, accuracy and reliability of data sources for road trauma and address any constraints, so that data quality for road trauma in Malawi is improved [8]. Assuming the apparent significant underreporting and incompleteness of road trauma data for both police and hospital-based registries, collating data from multiple sources has been proposed to improve the estimates for a nation's true road trauma burden [7][9].

Researchers consistently observe high levels of under-reporting of injuries and fatalities, particularly in LMIC, when the estimates are based on official records [8][10]. The problem of under-reporting is substantially higher for non-fatal injury cases and for vulnerable groups of road users (pedestrians, pedal cyclists, and motorcyclists) compared to fatal cases and vehicle occupants [11].

The capture-recapture method is a statistical method that is used to estimate the true population and can also be used to evaluate the completeness of data and identify biases between data sources [12]. In epidemiological applications, this method is useful in assessing accuracy of surveillance systems and providing more accurate rates, compared to those derived from individual data sources or aggregated data sources [13]. This method has been used in biological sciences to estimate hard-to-count populations [14] and has also been used to estimate incidence and magnitude of road traffic related injuries and deaths [8][15][16]

If significant action is not taken to resolve the bottlenecks in road safety work in LMIC including Malawi, the road safety crisis in Malawi will continue to worsen [17]. In this study, we assessed the quality of road trauma data reported by both hospital and police data sources in Ntcheu district to determine their accuracy, completeness and potential use for informing road safety initiatives and for understanding risk factors.

\section{Methods Study design and setting}

This study set out to evaluate the quality of road trauma data by assessing the completeness of road trauma data in Ntcheu district. This was a crosssectional study set in Ntcheu district, central Malawi, with a population of 659,608 [18].

\section{Ethical review and approval}

The study proposal received ethical clearance from the College of Medicine Research and Ethics Committee (ref number: P.07/19/2747). All personal identifying information were redacted prior to analysis and were substituted with a code. Furthermore, confidentiality and privacy policies for each institution 
were adhered to and data collection was done under the supervision of the responsible officers at each institution, to ensure that appropriate procedures were followed.

\section{Data sources}

\section{Hospital data source}

The hospital data were collected from the Health Management Information System (HMIS) set up by the government to manage health data in all health facilities in the country, triangulating data from the general casualty unit, operating theater and the mortuary department. The study investigator, supported by the emergency clinician and the HMIS officer for the facility, collected the data using a structured checklist prepared for the purpose of this study. All injuries and deaths resulting from road crashes reported to the facility from January 12018 to December 312018 were included. The HMIS is a sentinel type of surveillance for health data[19]. It includes data for patients as they show up at a health facility and is managed by an HMIS officer based at the facility. Kasambara et al. (2017) [20] highlight that data management through this platform is unsatisfactory in terms of accuracy, completeness, consistency and timeliness, making it unreliable to inform program planning and decision making.Even though this is the case with the data quality, this is also one the critical and popular sources of road trauma data in Malawi. Information on age, sex, road user type, time of the incident and injury deposition were gathered from this source.

\section{The traffic police data source}

The police are an important source of data for road injuries and deaths in Malawi. Assisted by the Station Traffic Officer (STO), the study investigator collected the road crash injury and death data for the year 2018. Fatalities include deaths that happened at the crash scene of the incident and those declared within one month of the incident. While only the police report deaths and injuries that occur outside the hospital, not all events are reported to them. This means that under-reporting by police-based registries is a widespread problem [11][21]. In their report of road deaths in Malawi, Schlottmann et al. (2017) [22] and Manyozo et al. (2018) [23] agree that police-based data tend to underestimate the true burden of road deaths in Malawi. We collected data on age, sex, road user type, time of the incident and injury deposition similar to the information collected from the hospital data source.

\section{Matching Criteria}

The capture-recapture methods evaluate the degree of overlap between the two data sources, which allows estimation of a corrected number, which is then used to estimate the degree of completeness of the sources being assessed [13]. In this study, the degree of overlap was determined through case matching. A match was made when gender, age (within five years), injury mechanism, location, and time (within three hours) matched, with one missing variable allowed as long as the other parameters were met. This case matching method was used in a similar study conducted in Malawi by Samuel et al. (2012) and was reported to be sensitive [24]. For crash location matching, data collectors have sufficient information on the studied road network and the district in general. Overlapping cases were coded " 1 " and non-overlapping cases as " 0 ". Record-linkage was performed manually.

\section{Simple Capture - Recapture analysis}

Let the number of events recorded in the hospital registry, $y$, the number of events recorded in the police accident reports, $x$, and the number of events reported in both the trauma registry and police accident reports, $z$. Number of events, $N$, is estimated as:

$$
N=\frac{(x+1)(y+1)}{(z+1)}-1
$$

The variance and $95 \%$ confidence interval of the estimate $\mathrm{N}$ follows as:

$$
\begin{gathered}
\operatorname{Var}(N)=\frac{(x+1)(y+1)(x-z)(y-z)}{(z-1)^{2}(z+2)} \\
95 \% C I=N \pm 1.96 \sqrt{\operatorname{Var}(N)}
\end{gathered}
$$

The estimated completeness of each database was calculated by dividing the number of road trauma events in each database by the ascertainment corrected number.

\section{Data analysis}

All quantitative data were verified to make sure that all cases captured were related road traffic crashes in Ntcheu district. Data from the two sources were explored separately before comparing quality between datasets. Categorical variables were explored using frequency tables. Continuous variables were summarized using means and standard deviation. The extent of non-reporting for each database was assessed using the capture-recapture methodology, while variable completeness was assessed using a checklist developed from the World Health Organization's injury surveillance core data set. All analyses were done using STAT14 [25]. 


\section{Results}

\section{Data quality assessment}

Both the police and hospital data sources had varying levels of missing data points, as presented in Table 1. The hospital data source lacked information on road user type, place of injury, time of injury and mechanism of injury. Table 2 shows that in $28 \%$ of the police records and $15 \%$ of the hospital records of road trauma, victim age was missing; in addition gender identity was missing for $9 \%$ of hospital road trauma cases compared to the $1 \%$ in the police records.

Table 1

A summary of data completeness for road trauma cases comparing police and hospital records based on the WHO core

\begin{tabular}{|c|c|c|}
\hline VARIABLES & Police database & Hospital database \\
\hline Victim ID & ) & ) \\
\hline Year/Month of injury & ) & ) \\
\hline Gender & 1 & I \\
\hline Age & ) & ) \\
\hline Home address & ) & I \\
\hline Type of road user & ) & \\
\hline Place of injury & ) & \\
\hline Time of injury & 1 & \\
\hline Mechanism of injury & ) & \\
\hline Severity of injury & I & I \\
\hline Outcome & ) & ) \\
\hline
\end{tabular}

For cases whose data were available across the two databases, the majority of the road trauma victims were in the age range of 15 to 44 years. The majority of road accident victims were male, accounting for $69.3 \%$ in the police records and $63.1 \%$ in the hospital records. Pedestrians were the highest affected road user category, contributing more than half of the all road injuries and deaths $(n=51,50.5 \%)$ reported by police in Ntcheu district. 
Table 2

A Summary of the distribution of road trauma victims by data variables showing proportion missing by type of database

\begin{tabular}{|c|c|c|}
\hline VARIABLES & Police database & Hospital database \\
\hline & $N=101$ & $N=130$ \\
\hline \multicolumn{3}{|l|}{ Age } \\
\hline $0-14$ & $20(19.8 \%)$ & $15(11.5 \%)$ \\
\hline $15-29$ & $17(16.8 \%)$ & $38(29.2 \%)$ \\
\hline $30-44$ & $26(25.7 \%)$ & $41(31.5 \%)$ \\
\hline $45-59$ & $13(12.9 \%)$ & $11(8.5 \%)$ \\
\hline $60+$ & $3(3.0 \%)$ & $6(4.6 \%)$ \\
\hline Missing age & $22(28 \%)$ & $19(14.6 \%)$ \\
\hline \multicolumn{3}{|l|}{ Gender } \\
\hline Male & 70 (69.3\%) & $82(63.1 \%)$ \\
\hline Female & 30 (29.69) & $36(27.7 \%)$ \\
\hline Missing & $1(0.99)$ & $12(9.2 \%)$ \\
\hline \multicolumn{3}{|l|}{ Road user type } \\
\hline Pedestrian & $51(50.5 \%)$ & - \\
\hline Cyclist & $18(17.8 \%)$ & - \\
\hline Passenger/vehicle occupant & $31(30.7 \%)$ & - \\
\hline Other i.e. cart rider & $1(0.99 \%)$ & - \\
\hline \multicolumn{3}{|l|}{ Time of injury } \\
\hline $6 a m-11: 59 a m$ & $6(5.9 \%)$ & - \\
\hline 12noon - 17:59 pm & $52(51.5 \%)$ & - \\
\hline $18 p m-5: 59 a m$ & $43(42.6 \%)$ & - \\
\hline \multicolumn{3}{|l|}{ Injury outcome } \\
\hline Dead & $72(71.3 \%)$ & $25(19.2 \%)$ \\
\hline Need clinical care & $29(28.7 \%)$ & $100(76.9 \%)$ \\
\hline Missing & - & $5(3.9 \%)$ \\
\hline
\end{tabular}

In the combined data set the lack of data on type of road user and time the injury in the hospital database meant that these variables had higher missingness rates, $58 \%$ and $58.4 \%$, respectively. The age group 30 to 44 years accounted for a third of all road injuries (66/231), and two-thirds of the total victims were men 144 (65.8\%). Table 3 presents a summary of the distribution of road trauma victims from the combined databases. 
Table 3

A Summary of the distribution of combined road trauma victims from both Ntcheu Police and Hospital records for the year 2018 by data variables showing proportions by data attribute, $\mathrm{N}=219$

\begin{tabular}{|c|c|c|}
\hline \multirow[t]{2}{*}{ VARIABLES } & \multicolumn{2}{|c|}{ Combined dataset, Police and Hospital based data } \\
\hline & Frequency $(\mathrm{N})$ & Percentage (\%) \\
\hline \multicolumn{3}{|l|}{ Age } \\
\hline $0-14$ & 33 & 15.1 \\
\hline $15-29$ & 52 & 23.7 \\
\hline $30-44$ & 66 & 30.1 \\
\hline $45-59$ & 24 & 11.0 \\
\hline $60+$ & 8 & 3.7 \\
\hline Missing age & 36 & 16.4 \\
\hline \multicolumn{3}{|l|}{ Gender } \\
\hline Male & 144 & 65.8 \\
\hline Female & 62 & 28.3 \\
\hline Missing & 13 & 5.9 \\
\hline \multicolumn{3}{|l|}{ Road user type } \\
\hline Pedestrian & 47 & 21.5 \\
\hline Cyclist & 15 & 6.9 \\
\hline Passenger/vehicle occupant & 29 & 13.2 \\
\hline Other i.e. cart rider & 1 & 0.5 \\
\hline Missing & 127 & 58.0 \\
\hline \multicolumn{3}{|l|}{ Time of injury } \\
\hline $6 a m-11: 59 a m$ & 6 & 2.7 \\
\hline $12 n o o n-17: 59 p m$ & 45 & 20.5 \\
\hline $18 p m-5: 59 a m$ & 40 & 18.3 \\
\hline Missing & 128 & 58.4 \\
\hline \multicolumn{3}{|l|}{ Injury outcome } \\
\hline Dead & 86 & 39.3 \\
\hline Need clinical care & 128 & 58.5 \\
\hline Missing & 5 & 2.3 \\
\hline
\end{tabular}

\section{Estimates on mortality from road trauma, Ntcheu district}

Out of the 101 road trauma cases recorded by the police, 72 deaths were recorded, indicating a Case Fatality Rate (CFR) of $71 \%$ for the district. The hospital data source recorded 25 deaths out of the 131 road trauma cases, indicating a CFR of $19 \%$. Using the Ntcheu district population reported for 2018 (659,608) [26] from the recent population and housing census, the estimated district level road trauma fatality rates were 11/100,000 and 4/100,000 for the police and hospital sources respectively. Fatality rate was estimated by diving the number of all deaths reported following a road crash in each data base by the Ntcheu district population reported in 2018.

\section{Estimating database completeness using capture - recapture methods.}

From the two databases, 13 case matches were identified, of which 10 were deaths, with $13 \%$ of the police-based data represented in the hospital database and $10 \%$ of the hospital data represented in the police database. From the two data sources, the ascertainment corrected number (estimated true burden) for road trauma in Ntcheu is 954 (95\% Cl: 457, 1451) road trauma cases and an estimated 173 deaths (95\% Cl: 89, 257) for the year 2018.

This means that based on the estimated true road trauma cases in 2018 in Ntcheu district, the 101 cases reported by the police constitute an $11 \%$ ascertainment and the 131 cases reported by the hospital constitute $14 \%$ of the total district level road trauma burden. Furthermore, the 72 deaths reported by the police represent $42 \%$ of the 2018 road deaths in Ntcheu district, while the 25 deaths recorded in the hospital database represent $14 \%$ of the road deaths. 
When combined (see Table 4), the police and hospital records reported $23 \%$ of all road trauma cases and $50 \%$ of all road deaths in Ntcheu district in the year 2018.

Table 4

comparison of reported and expected rates of traffic injury events

\begin{tabular}{|llll|}
\hline Data attribute & Reported events & Expected events & $95 \% \mathrm{Cl}$ \\
\hline Total road trauma events & 219 & 954 & $457-1451$ \\
\hline Total road deaths & 86 & 173 & $89-257$ \\
\hline Fatality rate & $13 / 100000$ & $26 / 100000$ & $22 / 100000-30 / 100000$ \\
\hline
\end{tabular}

\section{Discussion}

Our results show a high rate of under-reporting, and consequently lower ascertainment, for road deaths and injuries in Ntcheu district. These are estimated at $11 \%$ and $14 \%$ ascertainment for the police and hospital data sources respectively. This is compared to the established $80 \%$ ascertainment regarded by Bhalla et al. (2009) [21] as high-level completeness. In our study, more road deaths were reported by the police (72 deaths, $42 \%$ ascertainment) compared to the hospital (25 deaths, $14 \%$ ascertainment). The estimates we have reported are similar to what Chokotho et al. reported in 2011 in South Africa [10], and what Razzak et al. reported in 1998 in Pakistan [27], where the authors reported 50.6\% and 56.7\% rates of under-reporting of road deaths respectively.Furthermore, our estimates correspond closely to the 2018 Global Status Report on Road Safety which, using binomial regression models, estimated an $80 \%$ underreporting of road deaths in Malawi, considering the official reported 1122 deaths in 2016 and the estimated total of 5601 road deaths in the same year [3]. In other countries including China, Hu et al. [28] reported in 2010 that police recorded deaths at twice the level recorded by death registration data. Our results are therefore consistent with internationally observed rates of under-reporting, and further show that the estimates reported at district level in Ntcheu are way below the estimates that can be trusted to represent the true road trauma burden in the district[29].

In this study, the two databases differed greatly with respect to the ratio of fatal to non-fatal events. The hospital database had a much lower fatal:non-fatal ratio $(25: 101)$ compared to the police database (72:130). Furthermore, the police data captured twice as many road deaths as the hospital data source. Several reasons might explain this phenomenon. For example, most deaths at the scene of the crash are never reported to the hospital and thus are never registered by the health authorities. In addition, non-fatal cases rather than contacting the police mostly go straight to seek health care and hence are likely to be reported by the health services. Furthermore, the missing matching variables in both the police and hospital data sources are also an important consideration. The small number of matches could lead to a much larger road trauma burden estimated for the district, such that when compared with the reported cases, the ascertainment of each database would be highly diluted. Chokotho et al. (2011) refer to other factors that could contribute to the reduced level of completeness of road death data, including misclassification of road deaths by health services, especially deaths that occur a considerable time after the road crash [10].

The 2010 PLoS medicine editorial report [30] highlighted the need e, while highlighting the clear deficiencies in the data that is collected regarding road crashes. This has been clearly shown in this study, as the data sources demonstrated clear deficiencies in the key data variables of age, gender, time of injury and type of road user. The findings from this study further support the PLoS editorial in that there was massive under-reporting in both the police and hospital databases. This means that there is not a reliable picture of how many pedestrians, cyclists, motor vehicle users and other road users are dying in Ntcheu district. We suspect that this may be the situation in many, if not all, districts in Malawi.

The type of poor data quality observed in this study has been shown to affect the relevance and usefulness of such data in informing injury prevention initiatives [30][31]. Relevance of injury data is defined as the ability within the collected data to: (a) identify new and/or emerging injury mechanisms; (b) monitor injury trends over time; and (c) describe key characteristics of the injured population (i.e. using the WHO's core minimum data set for injury surveillance) [31]. Mitchel et al. (2009) further discuss data usefulness in terms of representation of the whole injury burden, as non-representative data may focus prevention efforts on populations that are not truly at risk, which could result in a misdirection of resources [31]. The poor-quality data reported in this study highlights the urgent need to improve the quality and completeness of road trauma data in Ntcheu district, let alone in the rest of Malawi.

The quality of reported data analysed in this study is worrying, especially considering that these data are used to produce official reports for policy consideration and program planning. Low quality data makes it difficult to target road safety interventions to groups at risk, to high crash road sections, and to times of the day when road crashes are more likely to occur. To support this, evidence from Sri Lanka suggests significant differences in age, road user type, injury severity, between events reported and those not reported (33\%) [32].

The health sector strategic plan (HSSP) 2017-2022 for Malawi [33] recognizes the huge burden of road trauma in Malawi, using an estimate of 35 deaths per 100,000 people. This number is well above the African regional average of 26.6 deaths per 100,000 people, and twice the global average of 17.4 deaths per 100,000 people. Despite these unsettling statistics, there has not been an adequate investment by public authorities to highlight this important public health and development problem in Malawi. The lack of accurate data may be one of the reasons that road safety is constantly understated as a major public health challenge, and why it has been under-resourced in national budgets.

Due to the poor quality of the data analysed in this study, we were not able to conduct a risk factor assessment for road trauma victims in Ntcheu district. Data sources from both the hospital and the police were marred by massive missing data. Risk factor assessments are possible with good quality data. For example, Loo et al. (2013) reported that road crash victims in Hong Kong over the age of 16 were most likely to be cyclists, pedestrians and back seat passengers [34]. They further reported that females involved in an accident were more likely than men to report their accident to the police. In our study, among 
the trauma cases with complete data $(42 \%)$, pedestrians $(21.5 \%, n=47)$ were the most affected amongst all road users and men were more affected, contributing to about $65.8 \%$ (144) of the road trauma burden among the reported events. Even though our data suggests massive underreporting, his result affirms locally the global concern for road safety for vulnerable road users and men as high risk groups [35][1].

Our results further show that police sources are more likely to report road fatalities compared to the hospital data sources, which reported more non-fatal cases. Farmer (2002) cautions the use of police data sources, as there are high chances of misclassification, and thus recommends the need to complement police-based data with that from hospitals [36]. In a study conducted in Hyderabad, comparing hospital-based and police-based data, people were more likely to report to the hospital than the police especially in hit-and-run situations [37].

\section{Study limitations}

This study was conducted based on a dynamic population, and so some assumptions for the use of capture-recapture methods were not met. This may affect interpretation of estimates reported. However, the methods has reliably been used in dynamic populations such as ours. Furthermore, deaths and injuries recorded in Ntcheu may include persons not resident in Ntcheu while the denominator used to calculate estimates is the Ntcheu local population. The estimates in this study may have also been affected by the very high levels of missing data observed in the reviewed files, which may have affected the estimates reported. We therefore encourage readers and users of this report to interpret these estimates with caution and due consideration of its potential limitations. However, our results are consistent with estimates reported by WHO, in which binomial regression methods were used to estimate the true burden and level of underreporting.

\section{Conclusions}

The road safety situation in Malawi appears to be worsening with the passing of each year [38][33]. Thacker (2007) [39] emphasized that what gets measured also gets done, and conversely that what is not measured is likely not to be done. The poor quality and incomplete data observed in this study may be the reason why there has not been corresponding significant investment in interventions to address the road safety situation in Ntcheu district specifically and Malawi generally, despite being one of the highest affected nations globally. It is therefore clear from this study that road traffic injury data in Ntcheu are in great need of improvement if they are to be used to inform prevention and progress evaluation. Stakeholders in road safety need to be aware that high quality data is a critical pre-requisite for assessing progress in road safety in Malawi, and that in its absence, any reported changes in road safety indicators may be misleading. However, the two data sources provide an opportunity for data linkage, to improve data quality for road trauma in Malawi. The national registration for Malawians provides a unique opportunity for data linkage between the police and the hospital data sources, as it provides a unique identification for each individual [40]. Stakeholders will need to review the operationalization of this strategy in future programs.

\section{Recommendations}

As a country, we have an opportunity to improve safety on our roads. Stakeholders working in road safety need to recognize the critical role of quality data in informing road safety initiatives, in understanding risk factors and in targeted program planning. They must therefore work to improve reporting, analysis and use of the road crash data. This study has provided an outline of critical data quality challenges in the relevant data sources. It is imperative for the responsible agencies and partners to work to resolve these data reporting and acquisition challenges. As indicated above, the national registration provides a unique identifier which provides an opportunity for data linkage between multiple sources to improve data acquisition and therefore quality of road crash data in Malawi.

\section{Declarations}

\section{Author contributions}

SM conceptualized the project; SM and RM designed the methods for the study. Data collection was led by SM. SM with support from RM analyzed the data. SM, RM and WS contributed to the development and revision of the manuscript and approved the final version.

\section{Acknowledgements}

We would like to thank the Ntcheu Police and the Ntcheu District Health Office for their invaluable support and input during our data collection period. We would also like to thank our colleagues who helped edit the manuscript to get it here.

\section{Ethics declarations}

\section{Ethical approval and consent to participate}

The study proposal was reviewed and approved by the College of Medicine Research Ethics Committee (COMREC) as part of the first authors Masters training ethics application on - (ref number: P.07/19/2747). Written Informed consent was not applicable as the investigators used de-identified secondary data from the two institutions. However, written permission was sought from the institutions. 


\section{Consent for publication}

Not applicable

\section{Competing interests}

The authors declare no conflicting interests.

\section{Availability of data for the study}

The datasets used and/or analyzed during the current study are available from the corresponding author on reasonable request

\section{Funding for the study}

The study was supported by the first author as this was his Masters training project. No external funding was sourced.

\section{References}

1. Staton C, Vissoci J, Gong E, Toomey N, Wafula R, Abdelgadir J, Zhou Y, Liu C, Pei F, Zick B, Ratliff CD. Road traffic injury prevention initiatives: a systematic review and metasummary of effectiveness in low- and middle-income countries. PloS one. 2016 Jan 6;11(1):e0144971.

2. International Federation of Red Cross and Road Crescent Societies. Road Safety, A call to action, 2009.

3. World Health Organization. Global status report on road safety 2018. World Health Organization; 2018.

4. World Health Organization. Global Status Report on Road Safety. 2015;340. Available from: www. who.int

5. Swedish Transportation Administration. Saving Lives Beyond 2020: Recommendations of the Academic Expert Group for the $3^{\text {rd }}$ Global Ministerial Conferene on Road Safety.

6. Samuel JC, Akinkuotu A, Villaveces A, Charles AG, Lee CN, Hoffman IF, Miller WC, Baloyi P, Hoffman M, Brown LB, Muyco AP. Epidemiology of injuries at a tertiary care center in Malawi. World journal of surgery. 2009 Sep 1;33(9):1836-41.

7. Mulwafu W, Chokotho L, Mkandawire N, Pandit H, Deckelbaum DL, Lavy C, et al. Trauma care in Malawi: A call to action. Malawi Med J. 2017;29(2):198202.

8. Samuel JC, Sankhulani E, Qureshi JS, Baloyi P, Thupi C, Lee CN, et al. Under-reporting of road traffic mortality in developing countries: Application of a capture-recapture statistical model to refine mortality estimates. PLoS One. 2012;7(2).

9. Samuel JC, Akinkuotu A, Baloyi P, Villaveces A, Charles A, Lee CN, et al. Hospital-based injury data in Malawi: strategies for data collection and feasibility of trauma scoring tools. Trop Doct . 2010;40(2):98-9.doi/10.1258/td.2009.090009

10. Chokotho L. AAssessing quality of existing data sources for road traffic injuries and their utility in informing injury prevention in the western cape province, South Africa, 2011.

11. WHO. Peden M, Scurfield R, Sleet D, Mohan D, Hyder AA, Jarawan E, Mathers C. World report on road traffic injury prevention.2004.

12. Morrison A, Stone DH. Capture-recapture: a useful methodological tool for counting traffic related injuries?. Injury Prevention. 2000 Dec 1;6(4):299-304

13. Meuleners LB, Lee AH, Cercarelli LR, Legge M. Estimating crashes involving heavy vehicles in Western Australia, 1999-2000: a capture-recapture method. Accident Analysis \& Prevention. 2006 Jan 1;38(1):170-4.

14. Razzak J. Estimating deaths and injuries due to road traffic accidents in Karachi, Pakistan, through the capture-recapture method. Int $\mathrm{J}$ Epidemiol. 2002;27(5):866-70.

15. Janstrup KH. Estimating road crashes in Denmark: An application of the capture-recapture method. InYoung Researcher Seminar 2013.

16. Lateef MU. Estimation of Fatalities Due to Road Traffic Crashes in Karachi , Pakistan , Using Capture - Recapture Method. 2010;

17. Sichembe W, Manyozo SD, Moodie R. The epidemiology of road traffic crashes in rural Zambia: A retrospective hospital-based study at Monze Mission Hospital. Medical Journal of Zambia. 2019;46(4):264-76.

18. Malawi Population and Housing Main Report. 2019 http://www.nsomalawi.mw/images/stories/data_on_line/demography/census_2018/2018 Malawi Population and Housing Census Main Report.pdf

19. Government of Malawi. Malawi National Health Information System Policy. 2015

20. Kasambara A, Kumwenda S, Kalulu K, Lungu K, Beattie T, Masangwi S, et al. Assessment of implementation of the health management information system at the district level in southern Malawi. Malawi Med J. 2017;29:240-6.

21. Bhalla K, Shahraz S, Bartels D, Abraham J. Methods for developing country level estimates of the incidence of deaths and non-fatal injuries from road traffic crashes. Int J Inj Contr Saf Promot. 2009;16(4):239-48.

22. Schlottmann F, Tyson AF, Cairns BA, Varela C, Charles AG. Road traffic collisions in Malawi: Trends and patterns of mortality on scene. Malawi medical journal. 2017;29(4):301-5.

23. Manyozo S, Moodie R. Road traffic collisions in malawi: Trends and patterns of mortality on scene. Malawi Med J. 2018;30(2). 
24. Samuel JC, Sankhulani E, Qureshi JS, Baloyi P, Thupi C, Lee CN, Miller WC, Cairns BA, Charles AG. Under-reporting of road traffic mortality in developing countries: application of a capture-recapture statistical model to refine mortality estimates. PloS one. 2012 Feb 15;7(2):e31091.

25. Publication ASP. Stata Bookstore / User's Guide, Release 14 [Internet]. Available from: http://www.stata.com/bookstore/users-guide/

26. Malawi Population and Housing preliminary Report. 2019 http://www.nsomalawi.mw/images/stories/data_on_line/demography/census_2018/2018 Malawi Population and Housing Census Main Report.pdf

27. Razzak JA, Luby SP. Estimating deaths and injuries due to road traffic accidents in Karachi, Pakistan, through the capture-recapture method. International journal of epidemiology. 1998 Oct 1;27(5):866-70.

28. Hu G, Baker T, Baker SP. Comparing road traffic mortality rates from police-reported data and death registration data in China. Bulletin of the World Health Organization. 2011;89:41-5.

29. Bhalla K, Harrison JE, Shahraz S, Fingerhut LA. Availability and quality of cause-of-death data for estimating the global burden of injuries. Bulletin of the World Health Organization. 2010;88:831-8c.

30. PLoS Medicine Editors. Preventing road deaths-time for data. PLoS Med. 2010 Mar 30;7(3):e1000257.

31. Mitchell RJ, Williamson AM, O'Connor R. The development of an evaluation framework for injury surveillance systems. BMC Public Health. 2009;9:1-14.

32. Periyasamy N, Lynch CA, Dharmaratne SD, Nugegoda DB, Østbye T. Under reporting of road traffic injuries in the district of Kandy, Sri Lanka. BMJ Open. 2013;3(11).

33. Government of Malawi, Ministry of Health. Health Sector Strategic Plan II 2. 2017;122: http://www.nationalplanningcycles.org/sites/default/files/planning_cycle_repository/malawi/health_sector_strategic_plan_ii_030417_smt_dps.pdf\%0Ahtt strategies

34. Loo BPY, Tsui KL. Factors affecting the likelihood of reporting road crashes resulting in medical treatment to the police. Inj Prev. 2007;13(3):186-9.

35. Patel A, Krebs E, Andrade L, Rulisa S, Vissoci JRN, Staton CA. The epidemiology of road traffic injury hotspots in Kigali, Rwanda from police data. BMC Public Health . 2016;16(1):697. 10.1186/s12889-016-3359-4

36. Farmer CM. Reliability of police-reported information for determining crash and injury severity. Traffic Inj Prev. 2003;4(1):38-44.

37. Dandona R, Kumar GA, Ameer MA, Reddy GB, Dandona L. Under-reporting of road traffic injuries to the police: results from two data sources in urban India. Injury prevention. 2008 Dec 1;14(6):360-5.

38. Mulwafu W, Chokotho L, Mkandawire N, Pandit H, Deckelbaum DL, Lavy C, Jacobsen KH. Trauma care in Malawi: A call to action. Malawi Medical Journal. 2017;29(2):198-202..

39. Thacker SB. Public health surveillance and the prevention of injuries in sports: what gets measured gets done. Journal of athletic training. 2007 Apr;42(2):171..

40. Government of Malawi. National Registration and Identification System. http://www.nrb.gov.mw/.

\section{Supplementary Files}

This is a list of supplementary files associated with this preprint. Click to download.

- TitlepageMANYOZO2020.docx 